NBER WORKING PAPER SERIES

THEORETICAL MODELS OF INEQUALITY TRANSMISSION ACROSS MULTIPLE GENERATIONS

Gary Solon

Working Paper 18790

http://www.nber.org/papers/w18790

\author{
NATIONAL BUREAU OF ECONOMIC RESEARCH \\ 1050 Massachusetts Avenue \\ Cambridge, MA 02138 \\ February 2013
}

This paper was prepared for the Panel Study of Income Dynamics conference on "Inequality across Multiple Generations," held at the University of Michigan in September 2012. I am grateful for helpful comments from participants at the conference and for generous advice from John Laitner. The views expressed herein are those of the author and do not necessarily reflect the views of the National Bureau of Economic Research.

NBER working papers are circulated for discussion and comment purposes. They have not been peerreviewed or been subject to the review by the NBER Board of Directors that accompanies official NBER publications.

(c) 2013 by Gary Solon. All rights reserved. Short sections of text, not to exceed two paragraphs, may be quoted without explicit permission provided that full credit, including (C) notice, is given to the source. 
Theoretical Models of Inequality Transmission across Multiple Generations

Gary Solon

NBER Working Paper No. 18790

February 2013

JEL No. J62

\title{
ABSTRACT
}

Existing theoretical models of intergenerational transmission of socioeconomic status have strong implications for the association of outcomes across multiple generations of a family. These models, however, are highly stylized and do not encompass many plausible avenues for transmission across multiple generations. This paper extends existing models to encompass some of these avenues and draws out empirical implications for the multigenerational persistence of socioeconomic status.

\author{
Gary Solon \\ Department of Economics \\ Michigan State University \\ East Lansing, MI 48824-1038 \\ and NBER \\ solon@msu.edu
}




\section{Theoretical Models of Inequality Transmission across Multiple Generations}

The other papers prepared for this conference present empirical evidence on the persistence of socioeconomic status across more than two generations. In contrast, my paper theorizes on the subject. It's a dirty job, but someone ought to do it! My hope is that the conceptualization provided by a theoretical framework will aid in the interpretation and further development of empirical research on multigenerational inequality.

Section 1 of this paper reviews existing theoretical models of intergenerational transmission. It notes an initially surprising (and, I suspect, empirically refutable) implication about the association between grandparents' and children's status conditional on the parents' status. I will suggest that more realistic predictions can be obtained by extending the existing theory to encompass several additional ways in which grandparents' socioeconomic status may foretell children's outcomes. In Section 2, I will present three such extensions and discuss the empirical implications. Section 3 will summarize and discuss the findings.

\section{A Review of Existing Theory}

My point of departure is a simplified version of the model in Solon (2004), which adapted the classic model of Becker and Tomes (1979) to rationalize the double-log functional form of the regression equations typically estimated in empirical studies of intergenerational income mobility. ${ }^{1}$ The model begins by assuming that family $i$ contains one parent of generation $t-1$ and one child of generation $t$. The family must allocate the parent's lifetime earnings $y_{i, t-1}$ between the parent's own consumption $C_{i, t-1}$ and investment $I_{i, t-1}$ in the child's human capital. The resulting budget constraint,

$$
y_{i, t-1}=C_{i, t-1}+I_{i, t-1} \text {, }
$$

\footnotetext{
${ }^{1}$ The present paper's simplification relative to Solon (2004) is that it leaves out taxation and government investment in children. In Solon (2004), I wished to discuss the effect of public investment in children's human capital on intergenerational mobility. In the present paper, including a government role would clutter the model without affecting the model's implications for the structure of multigenerational persistence.
} 
assumes that the parent cannot borrow against the child's prospective earnings and does not bequeath financial assets to the child. ${ }^{2}$

The technology translating the investment $I_{i, t-1}$ into the child's human capital $h_{i t}$ is

$$
h_{i t}=\theta \log I_{i, t-1}+e_{i t}
$$

where $\theta>0$ represents a positive marginal product for human capital investment, the semi-log functional form imposes decreasing marginal product, and $e_{i t}$ denotes the human capital endowment the child receives regardless of the family's conscious investment choices. This endowment includes both inheritance of genetic traits and cultural inheritance, such as the effects of parental role-modeling. In this section, I follow Becker and Tomes (1979) in assuming that $e_{i t}$ follows the first-order autoregressive process

$$
e_{i t}=\delta+\lambda e_{i, t-1}+v_{i t}
$$

where $v_{i t}$ is a white-noise error term and the heritability coefficient $\lambda$ lies between 0 and 1.

I also assume that the child's lifetime income $y_{i t}$ is determined by the semi-log earnings function

$$
\text { (4) } \quad \log y_{i t}=\mu+p h_{i t}
$$

where $p$ is the earnings return to human capital. Substituting equation (2) into equation (4) yields

$$
\text { (5) } \quad \log y_{i t}=\mu+\gamma \log I_{i, t-1}+p e_{i t}
$$

where $\gamma=\theta p$ is the elasticity of the child's income with respect to investment in the child's human capital. I will henceforth refer to $\gamma$ as the "earnings return to human capital investment."

\footnotetext{
${ }^{2}$ See Becker and Tomes (1986) for an analysis that relaxes this assumption.
} 
How does the family decide how much to invest in the child's human capital? I assume that the parent divides her or his income $y_{i, t-1}$ between own consumption $C_{i, t-1}$ and investment $I_{i, t-1}$ in the child's human capital so as to maximize the Cobb-Douglas utility function

$$
U_{i}=(1-\alpha) \log C_{i, t-1}+\alpha \log y_{i t} .
$$

The altruism parameter $\alpha$, which lies between 0 and 1, measures the parent's taste for $y_{i t}$ relative to $C_{i, t-1}$. If the parent is cognizant of equations (1) through (5) and the variables therein, this utility function can be rewritten as

$$
U_{i}=(1-\alpha) \log \left(y_{i, t-1}-I_{i, t-1}\right)+\alpha \mu+\alpha \gamma \log I_{i, t-1}+\alpha p e_{i t},
$$

which expresses the objective function in terms of the choice variable $I_{i, t-1}$.

The first-order condition for maximizing this utility function is

$$
\partial U_{i} / \partial I_{i, t-1}=-(1-\alpha) /\left(y_{i, t-1}-I_{i, t-1}\right)+\alpha \gamma / I_{i, t-1}=0
$$

Solving for the optimal choice of $I_{i, t-1}$ yields

$$
I_{i, t-1}=\{\alpha \gamma /[1-\alpha(1-\gamma)]\} y_{i, t-1}
$$

This simple result has several intuitive implications. First, higher-income parents use part of their greater wherewithal to invest more in their children's human capital. Second, parents' investment in their children's human capital is increasing in parental altruism $\alpha$. Third, parental investment also is increasing in $\gamma$, the earnings return to human capital investment. In other words, parents are more inclined to invest in their children's human capital when the payoff is higher. 
It is now straightforward to proceed to deriving first the implications for the intergenerational income association between $y_{i t}$ and $y_{i, t-1}$, and then the implications for the role of grandparents. Substituting equation (9) for $I_{i, t-1}$ into equation (5) yields the regression equation

$$
\log y_{i t}=\mu^{*}+\gamma \log y_{i, t-1}+p e_{i t}
$$

with intercept $\mu^{*}=\mu+\gamma \log \{\alpha \gamma /[1-\alpha(1-\gamma]\}$. At first glance, equation (10) looks like the loglinear intergenerational income regression frequently estimated by empirical researchers. Viewed as the error term, however, $p e_{i t}$ is not well-behaved. It is correlated with the regressor $\log y_{i, t-1}$ because the child's endowment $e_{i t}$ and the parent's log income $\log y_{i, t-1}$ both depend on the parent's endowment $e_{i, t-1}$.

In fact, equation (10) is a familiar entity in introductory econometrics textbooks. It is the first-order autoregression of $\log y_{i t}$ with a serially correlated error term that itself follows a firstorder autoregression, as shown in equation (3). In steady state, in which $\log y_{i t}$ and $\log y_{i, t-1}$ have the same variance, the slope coefficient in the population regression of $\log y_{i t}$ on $\log y_{i, t-1}$ is equivalent to the correlation between $\log y_{i t}$ and $\log y_{i, t-1}$. In the present context, this quantity, which I will denote as $\beta$, is the steady-state intergenerational income elasticity. As shown in Greene (2012, p. 919), this quantity is the sum of the two autoregressive parameters, the slope coefficient in equation (10) and the serial correlation coefficient in equation (3), divided by 1 plus their product. Thus, the steady-state intergenerational income elasticity is

$$
\beta=(\gamma+\lambda) /(1+\gamma \lambda)
$$

Equation (11) indicates that the intergenerational income elasticity is positive for both of two reasons - because $\gamma$ is positive (i.e., richer parents' greater investment in their children's human capital makes their children richer) and because $\lambda$ is positive (i.e., richer parents tend to have more favorable endowments, which tend to be passed on to their children through genetic 
and cultural inheritance). Suppose, for example, that $\gamma=0.3$ and $\lambda=0.2$ (or vice versa, as the symmetry in how $\gamma$ and $\lambda$ enter equation (11) will lead to the same outcome). Then the intergenerational income elasticity is $\beta=(0.3+0.2) /[1+(0.3)(0.2)] \cong 0.47$.

What is most pertinent for this conference, though, is what the model implies about the role of grandparents. Lagging equation (10) by one generation, multiplying it by the heritability coefficient $\lambda$, and subtracting the result from equation (10) yield the second-order autoregression

$$
\log y_{i t}=(1-\lambda)\left(\mu^{*}+p \delta\right)+(\gamma+\lambda) \log y_{i, t-1}-\gamma \lambda \log y_{i, t-2}+p v_{i t}
$$

In this regression of the child's log income on both parental and grandparental log income, the coefficient of parental log income is positive, but the coefficient of grandparental log income is a small negative quantity! For example, with $\gamma=0.3$ and $\lambda=0.2$, the coefficient of parental log income is 0.5 , and the coefficient of grandparental log income is -0.06 . This implication of a negative coefficient for grandparental income, first noted by Becker and Tomes (1979), is initially surprising, but it does not really mean that an exogenous increase in grandparental income harms the child's income. Rather, it reflects a subtle implication of higher grandparental income conditional on the amount of parental income. If the parent did not earn more despite the advantages of higher grandparental income, this signals that the parent got a poor draw on her or his genetic/cultural endowment, and that poor draw tends to be passed on to some extent to the child.

Intergenerational mobility scholars sometimes presume that intergenerational autocorrelations decline geometrically - that is, that the correlation between grandparent and child is the square of the parent-child correlation, that the correlation between great-grandparent and child is the cube, etc. There is no particular basis for that presumption, and it is contradicted by the second-order autoregressive structure of equation (12). ${ }^{3}$ In fact, if the grandparental coefficient in equation (12) is really negative, the autocorrelations decline more rapidly than geometrically. For example, with $\gamma=0.3, \lambda=0.2$, and hence about a 0.47 correlation between parent and child log incomes, applying standard results on the autocorrelations implied by a

${ }^{3}$ Other analyses that have taken exception to the naïve presumption of geometrically declining autocorrelations include Eide and Showalter (2000) and Stuhler (2012). 
second-order autoregressive process (Box, Jenkins, and Reinsel, 1994, p. 60) shows that the correlation between the grandparent's and child's log incomes is about 0.18 , somewhat less than the square of 0.47 . And the correlation between the great-grandparent's and child's log incomes is only about 0.06 .

But is the model's prediction of a negative grandparental coefficient in equation (12) realistic? In principle, the prediction is testable with multigenerational data. Indeed, Behrman and Taubman (1985) did explicitly test the prediction by estimating an equation like equation (12) for years of education rather than log income. Various versions of their results show statistically insignificant coefficient estimates of either sign for grandparental education, ${ }^{4}$ so Behrman and Taubman (p. 150) concluded that "Becker's model is rejected for this data set." In truth, however, Behrman and Taubman's sample size was not large enough to find statistically significant evidence of a small negative grandparental coefficient even if the model's prediction is exactly right.

As exemplified by papers at this conference, however, numerous empirical researchers are now using various new data sets to re-examine multigenerational associations in socioeconomic status. Not only are these studies still failing to find evidence of a negative coefficient for grandparental status; some of them are estimating statistically significant positive coefficients. Relatedly, some are finding that intergenerational autocorrelations decline more slowly than at a geometric rate. ${ }^{5}$

I am not terribly surprised by these findings. The reason I am not surprised is that existing theoretical models are highly stylized and do not encompass several plausible ways in which grandparents' socioeconomic status may foretell children's outcomes. Here are five examples. First, as noted in Robert Mare's (2011) presidential address to the Population Association of America, in some families, grandparents as well as parents invest in the children's human capital. Second, in families in which the grandparents are actively involved in the children's lives, the grandparents are likely to contribute to cultural inheritance. Third, genetic transmission is really more complicated than the simple first-order autoregression assumed in

\footnotetext{
${ }^{4}$ Warren and Hauser (1997) reported similar results for regressions of child's education on various measures of parental and grandparental socioeconomic status. That paper also includes a succinct summary of other multigenerational empirical studies as of 1997.

${ }^{5}$ See Modin and Fritzell (2009), Campbell and Lee (2011), Zeng and Xie (2011), Lindahl et al. (2012), Clark and Cummins (2012), and Long and Ferrie (2012). A classic early study of multigenerational autocorrelations is Hodge (1966).
} 
equation (3). Recognizing the reasons that manifestations of family genetic traits can "skip a generation" is another way of opening up the possibility of a positive coefficient for grandparents' status. Fourth, discrimination and other types of what George Borjas (1995) has dubbed "ethnic capital" can generate group effects that would be correlated with the status of both parents and grandparents. Finally, measurement error could create the appearance of grandparental effects even when they are not really present. Accordingly, in the next section, I extend the model of this section to incorporate some of these processes.

\section{Extending the Theory to Encompass Additional Avenues of Multigenerational Transmission}

Let's start with the possibility of grandparental investment in children's human capital. If the grandparents' preferences for such investment line up with those of the parents, then the model of the previous section needs no modification at all. In this case, the grandparent can just invest in the parent as modeled in Section 1 and trust the parent to "pass it on" in the way that they mutually prefer. $^{6}$ On the other hand, if the grandparent would prefer either more or less investment in the child's human capital than the parent does, matters are more complicated. For example, the grandparent's choice of how much to invest in the child would have to take account of how the parent's investment choice would respond to the grandparent's investment. I would be happy to see someone work out the equilibrium of that game, but that project might call for a professional theorist, not an amateur like me.

In contrast, the other avenues of multigenerational transmission mentioned at the end of Section 1 are so easy to model that even I can do it. First, let's reconsider the assumption in equation (3) that the child's direct genetic and cultural inheritance comes only from the parent. As noted in Chapter 6 of Becker (1981), the endowment model easily can be generalized by adding endowment contributions from other relatives to the right side of equation (3). Thus, to add the possibility of a grandparental contribution (beyond the contribution mediated through the parent), just extend equation (3) to

$$
e_{i t}=\delta+\lambda_{1} e_{i, t-1}+\lambda_{2} e_{i, t-2}+v_{i t}
$$

\footnotetext{
${ }^{6}$ I am grateful to John Laitner for this insight.
} 
where $0 \leq \lambda_{2}<\lambda_{1}<1$. Then it is straightforward to redo all the subsequent math in Section 1 based on equation (13) instead of equation (3).

For purposes of this conference, the most important implication is that equation (12) gets generalized to

$$
\begin{gathered}
\log y_{i t}=\left(1-\lambda_{1}-\lambda_{2}\right)\left(\mu^{*}+p \delta\right)+\left(\gamma+\lambda_{1}\right) \log y_{i, t-1}+\left(\lambda_{2}-\gamma \lambda_{1}\right) \log y_{i, t-2} \\
-\gamma \lambda_{2} \log y_{i, t-3}+p v_{i t} .
\end{gathered}
$$

If $\lambda_{2}=0$, equation (14) specializes back to equation (12). But if $\lambda_{2}>0$, equation (14) differs from equation (12) in two notable ways. First, now great-grandparental log income enters with a negative coefficient, which is even smaller in magnitude than the one that appeared for grandparental log income in equation (12). Second, the coefficient for grandparental log income might be positive now because of the incorporation of a grandparental contribution to the child's genetic/cultural inheritance. In particular, the grandparental coefficient is positive if $\lambda_{2} / \lambda_{1}>\gamma$. Thus, if the advent of new and better multigenerational data demonstrates that the grandparental coefficient is indeed positive, one possible interpretation will be that grandparental contributions to genetic or cultural inheritance loom large enough in enough families to dominate the negative “effect” discussed in Section 1.

A different extension of the model is that various types of "ethnic capital" might cause the intercept in equation (12) or (14) to differ across subpopulations. In particular, a group with a lower $\mu$ (the intercept in the earnings function shown as equation (4)) or a lower altruism parameter $\alpha$ would have a lower intercept in equation (12) or (14). Suppose, for example, that racial discrimination in the United States causes African-American families to have a lower earnings function intercept $\mu$ and therefore lower intercepts in equations (10), (12), and (14). ${ }^{7}$ Then a failure to model the between-group difference in intercepts in equation (12) or (14) amounts to omission of group fixed effects. Applying the usual omitted-variables-bias analysis shows that, because both parental log income and grandparental log income (as well as greatgrandparental log income in equation (14)) have positive partial correlations with the omitted

\footnotetext{
${ }^{7}$ Indeed, Hertz's (2005) estimation of equation (10) by race in the Panel Study of Income Dynamics does show a substantially smaller intercept for African-Americans than for whites.
} 
group effect, all the ancestral coefficients are pushed in a positive direction. This would be a force towards slower-than-geometric decay in multigenerational autocorrelations. ${ }^{8}$ This suggests another possible interpretation if new evidence shows positive coefficients for the status of grandparents or earlier ancestors, especially if substantially positive coefficients appear even for distant ancestors in an extended version of equation (14). Of course, if within-group sample sizes are large enough, an obvious way to check the applicability of this interpretation is to control for group fixed effects in the estimation of regressions like equation (12) or (14).

Finally, even if the grandparental coefficient is not really positive, it might appear to be because of measurement error. Suppose, for example, that the intergenerational autoregression is first-order autoregressive, with a 0.5 coefficient for parental status and zero coefficients for grandparents, great-grandparents, etc. Then the true intergenerational autocorrelations would decline geometrically: a 0.5 correlation between child and parents, 0.25 between child and grandparents, 0.125 between child and great-grandparents, etc. But now suppose that each generation's status is measured with classical (i.e., purely random) measurement error. And suppose that the measured variation in each generation consists 80 percent of true variation and 20 percent of measurement noise. Then each of the measured autocorrelations would be attenuated by a factor of 0.8 . That is, the measured autocorrelations would tend towards 0.4 between child and parents, 0.2 between child and grandparents, 0.1 between child and greatgrandparents, etc. And because these measured autocorrelations decline more slowly than geometrically, fitting an autoregression of child's status on both parental and grandparental status would result in a positive coefficient estimate for grandparental status. Empirical analysts of multigenerational inequality therefore need to be alert to the possibility that apparent multigenerational influences could arise as an artifact of measurement problems.

\section{Summary and Discussion}

As shown in Section 1, existing theoretical models in the tradition of Becker and Tomes (1979) predict that a second-order autoregression of child's socioeconomic status on the status of both parents and grandparents will involve a small negative coefficient for grandparental status. Correspondingly, intergenerational autocorrelations should decline at a faster-than-geometric

\footnotetext{
${ }^{8}$ This possibility was previously discussed in Section VI of Becker and Tomes (1979). Footnote 13 in that section also discusses not-so-fixed group effects that evolve gradually over time.
} 
rate. Accumulating empirical evidence, however, suggests that, in at least some times and places, grandparental coefficients are positive, and autocorrelations decline more slowly than geometrically. This evidence does not mean that the Becker-Tomes analysis is wrong as far as it goes; rather, it means that the analysis does not go far enough. In Section 2, I have suggested several straightforward extensions of the Becker-Tomes analysis that can account for positive higher-order coefficients in multigenerational autoregressions and for autocorrelations that decline more slowly than geometrically.

A major virtue of the Becker-Tomes analysis was its demonstration that positive intergenerational correlations in socioeconomic status can arise from the greater wherewithal of richer parents to invest in their children's human capital, from genetic or cultural inheritance, or from all of the above. Because these different sources of intergenerational status transmission have similar empirical manifestations, it is difficult to tell them apart. A similar lesson can be drawn from Section 2 of the present paper. A multitude of different processes can generate positive higher-order coefficients in multigenerational autoregressions and autocorrelations that decay more slowly than geometrically. Distinguishing those processes from each other therefore will be a difficult challenge for scholars investigating multigenerational inequality. 


\section{$\underline{\text { References }}$}

Becker, Gary S. A Treatise on the Family. Cambridge, MA: Harvard University Press, 1981.

Becker, Gary S., and Nigel Tomes. “An Equilibrium Theory of the Distribution of Income and Intergenerational Mobility.” Journal of Political Economy 87 (December 1979), pp. 11531189.

Becker, Gary S., and Nigel Tomes. "Human Capital and the Rise and Fall of Families.” Journal of Labor Economics 4 (July 1986), pp. S1-S39.

Behrman, Jere, and Paul Taubman. "Intergenerational Earnings Mobility in the United States: Some Estimates and a Test of Becker’s Intergenerational Endowments Model.” Review of Economics and Statistics 67 (February 1985), pp. 144-151.

Borjas, George J. “Ethnicity, Neighborhoods, and Human-Capital Externalities.” American Economic Review 85 (June 1995), pp. 365-390.

Box, George E.P., Gwilym M. Jenkins, and Gregory C. Reinsel. Time Series Analysis: Forecasting and Control. $3^{\text {rd }}$ edition. Englewood Cliffs: Prentice Hall, 1994.

Campbell, Cameron, and James Z. Lee. “Kinship and the Long-Term Persistence of Inequality in Liaoning, China, 1749-2005.” Chinese Sociological Review 44 (Fall 2011), pp. 71-103.

Clark, Gregory, and Neil Cummins. "What Is the True Rate of Social Mobility? Surnames and Social Mobility in England, 1800-2012.” Unpublished manuscript, 2012.

Eide, Eric R., and Mark H. Showalter. “A Note on the Rate of Intergenerational Convergence of Earnings.” Journal of Population Economics 13 (March 2000), pp. 159-162.

Greene, William H. Econometric Analysis. 7th edition. Upper Saddle River: Prentice Hall, 2012

Hertz, Tom. "Rags, Riches, and Race: The Intergenerational Economic Mobility of Black and White Families in the United States.” Chapter 5 in Samuel Bowles, Herbert Gintis, and Melissa Osborne Groves (eds.), Unequal Chances: Family Background and Economic Success. Princeton: Princeton University Press, 2005.

Hodge, Robert W. “Occupational Mobility as a Probability Process.” Demography 3 (1966), pp. 19-34.

Lindahl, Mikael, Mårten Palme, Sofia Sandgren Massih, and Anna Sjögren. “The Intergenerational Persistence of Human Capital: An Empirical Analysis of Four Generations.” IZA Discussion Paper No. 6463, 2012. 
Long, Jason, and Joseph Ferrie. "Grandfathers Matter(ed): Occupational Mobility across Three Generations in the U.S. and Britain, 1850-1910.” Unpublished manuscript, 2012.

Mare, Robert D. “A Multigenerational View of Inequality.” Demography 48 (February 2011), pp. 1-23.

Modin, Bitte, and Johan Fritzell. "The Long Arm of the Family: Are Parental and Grandparental Earnings Related to Young Men’s Body Mass Index and Cognitive Ability?” International Journal of Epidemiology 38 (June 2009), pp. 733-744.

Solon, Gary. "A Model of Intergenerational Mobility Variation over Time and Place.” Chapter 2 in Miles Corak (ed.), Generational Income Mobility in North America and Europe. Cambridge, UK: Cambridge University Press, 2004.

Stuhler, Jan. “Mobility across Multiple Generations: The Iterated Regression Fallacy.” IZA Discussion Paper No. 7072, 2012.

Warren, John Robert, and Robert M. Hauser. "Social Stratification across Three Generations: New Evidence from the Wisconsin Longitudinal Study.” American Sociological Review 62 (August 1997), pp. 561-572.

Zeng, Zhen, and Yu Xie. “The Effects of Grandparents on Children’s Schooling: Evidence from Rural China.” Unpublished manuscript, 2011. 